\title{
A FLEXIBILIZAÇÃO PROCEDIMENTAL NA \\ JUSTIÇA CRIMINAL: OS IMPACTOS DO CPC/15 E AS DISTINTAS PREMISSAS DO PROCESSO PENAL
}

PROCEDURAL FLEXIBILITY IN CRIMINAL JUSTICE: IMPACTS OF CPC/15 AND THE DIFFERENT PREMISES OF CRIMINAL PROCEDURE

\section{LA FLEXIBILIZACIÓN PROCESAL EN LA JUSTICIA CRIMINAL: LOS IMPACTOS DEL CPC/15 Y LAS DISTINTAS PREMISAS DEL PROCESO PENAL}

\section{Vinicius Gomes de Vasconcellos'}

Licença CC BY:

Artigo distribuído sob os termos Creative Commons, permite uso e distribuição irrestrita em qualquer meio desde que $o$ autor credite a fonte original.

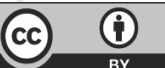

Resumo: Este artigo pretende analisar as premissas e o cenário de flexibilização procedimental que se expande no direito processual brasileiro, especialmente considerando os impactos do Código de Processo Civil de 2015 na esfera processual penal a partir de revisão bibliográfica. Diante disso, almeja-se examinar os seguintes problemas: 1) as premissas teóricas da flexibilização procedimental do processo civil podem ser transplantadas ao processo penal?; 2) considerando eventuais distinções entre tais instrumentos e suas funções, a relativização da necessidade de respeito à legalidade pode ser aceita no processo penal? A partir das diferenças entre as esferas penal e civil, conclui-se que as premissas de aplicação da flexibilização procedimental não podem ser transplantadas da esfera civil à penal sem revisão crítica, de modo que as possibilidades de flexibilizações procedimentais legais alternativas e consensuais devem ser analisadas com cautela e limitadas em âmbito criminal.

Palavras-chave: Flexibilização procedimental; Processo Civil; Processo Penal; Relações; Teoria Geral do Processo.

Abstract: This paper analyzes the premises and the scenario of procedural flexibility in Brazilian procedural law, especially considering the impacts of the Civil Procedure Code of 2015 on the sphere of criminal procedure. This is done through a bibliographic review. It examines the following problems: 1) Can the theoretical premises of procedural flexibilization in civil procedure be transplanted to criminal proceedings?; and 2) Considering the distinctions between these instruments and their functions, can the relativization of the need to respect legality be accepted in criminal procedure? Bearing in mind the differences between the criminal and civil spheres, this study concludes that the premises of application of procedural flexibilization cannot be transplanted from the civil to the criminal sphere without a critical revision, therefore, the possibilities of alternative and consensual procedural flexibilizations must be analyzed with caution and limited in criminal procedure.

1 Doutor em Direito pela Universidade de São Paulo, com período de sanduíche na Universidad Complutense de Madrid/ESP (bolsa PDSE/ CAPES) e estágio de pós-doutoramento pela Universidade Federal do Rio de Janeiro. Mestre em Ciências Criminais pela PUCRS. Professor permanente do Instituto Brasiliense de Direito Público - IDP/DF (mestrado/doutorado). Professor efetivo da Universidade Estadual de Goiás. Editor-chefe da RBDPP. Assessor de Ministro no Supremo Tribunal Federal. orcid.org/0000-0003-2020-5516. Contato: vinicius.vasconcellos@ ueg.br 
Keywords: Procedural flexibility; Civil procedure; Criminal procedure; Relations; General Theory of Process.

Resumen: Este artículo pretende analizar las premisas y el escenario de flexibilización procesal que se expande en el derecho procesal brasileño, especialmente considerando los impactos del Código de Proceso Civil de 2015 en la esfera procesal penal a partir de la revisión bibliográfica. Delante de esto, se desea examinar los siguientes problemas: 1) ¿las premisas teóricas de la flexibilización procesal del proceso civil pueden ser transplantadas al proceso penal?; 2) considerando eventuales distinciones entre tales instrumentos y sus funciones, ¿la relativización de la necesidad de respeto a la legalidad puede ser aceptada en el proceso penal? A partir de las diferencias entre las esferas penales y civiles, se concluyó que las premisas de aplicación de la flexibilización procesal no pueden ser transplantadas de la esfera civil a la penal sin revisión crítica, de modo que las posibilidades de flexibilizaciones procesales legales alternativas y consensuales deben ser analizadas con cautela y limitadas en ámbito criminal.

Palabras clave: Flexibilización procesal; Proceso Civil; Proceso Penal; Relaciones; Teoría General del Proceso.

\section{INTRODUÇÃO}

Com o surgimento do novo Código de Processo Civil de 2015, inúmeras questões pertinentes e discussões de complexidade ímpar são atuais e relevantes. Sem dúvidas, diversos desses problemas acarretam impactos também ao direito processual penal, tanto para aqueles que defendem a existência de uma teoria geral do processo como para quem a nega. Certamente, importantes contribuições na nova legislação processual civil podem advir ao processo penal, como o reforço na efetividade do contraditório previsto nos artigos $9^{\circ}$ e $10^{2}$ (que podem impactar na visão majoritária sobre a sua desnecessidade em casos de emendatio libelli no processo penal) e as definições de o que "não se considera" uma decisão adequadamente motivada, segundo o parágrafo primeiro do art. 489. ${ }^{3}$

Entretanto, também há inovações que podem ocasionar tensões em caso de importações acríticas da esfera civil à penal. E um exemplo de ponto passível de intensas e importantes discussões é a possibilidade de flexibilização procedimental, que autorizaria a desatenção à sequência de atos ou a suas formalidades em razão de uma adequação às necessidades do caso concreto, pelo próprio julgador ou por acordo entre as partes.

2 Art. 9o Não se proferirá decisão contra uma das partes sem que ela seja previamente ouvida; Art. 10 . O juiz não pode decidir, em grau algum de jurisdição, com base em fundamento a respeito do qual não se tenha dado às partes oportunidade de se manifestar, ainda que se trate de matéria sobre a qual deva decidir de ofício.

3 Art. 489, § 1ำ Não se considera fundamentada qualquer decisão judicial, seja ela interlocutória, sentença ou acórdão, que: I - se limitar à indicação, à reprodução ou à paráfrase de ato normativo, sem explicar sua relação com a causa ou a questão decidida; II - empregar conceitos jurídicos indeterminados, sem explicar o motivo concreto de sua incidência no caso; III - invocar motivos que se prestariam a justificar qualquer outra decisão; IV - não enfrentar todos os argumentos deduzidos no processo capazes de, em tese, infirmar a conclusão adotada pelo julgador; V - se limitar a invocar precedente ou enunciado de súmula, sem identificar seus fundamentos determinantes nem demonstrar que o caso sob julgamento se ajusta àqueles fundamentos; VI - deixar de seguir enunciado de súmula, jurisprudência ou precedente invocado pela parte, sem demonstrar a existência de distinção no caso em julgamento ou a superação do entendimento. 
Diante disso, a partir de revisão bibliográfica, este trabalho pretende analisar os seguintes problemas: 1) as premissas teóricas da flexibilização procedimental do processo civil podem ser transplantadas ao processo penal?; 2) considerando eventuais distinções entre tais instrumentos e suas funções, a relativização da necessidade de respeito à legalidade pode ser aceita no processo penal? A partir das diferenças entre as esferas penal e civil, conclui-se que as premissas de aplicação da flexibilização procedimental não podem ser transplantadas da esfera civil à penal sem revisão crítica, de modo que as possibilidades de flexibilizações procedimentais legais alternativas e consensuais devem ser analisadas com cautela e limitadas em âmbito criminal.

\section{A FLEXIBILIZAÇÃO PROCEDIMENTAL E SUAS PREMISSAS TEÓRICAS NO DIREITO PROCESSUAL}

Em um cenário de paulatinas alterações e intensos debates no direito processual, o Código de Processo Civil (CPC) de 2015 surgiu com importantes inovações, como a introdução de mecanismos para possibilitar a flexibilização procedimental. Trata-se da "adaptação dos procedimentos ao caso em concreto", ${ }_{4}^{4}$ em que as normas previstas na legislação são moldadas ou desconsideradas para aplicação de ritos e formas compatíveis com a resolução do conflito do modo mais célere possível.

Há, assim, uma valorização do procedimento na teoria do direito processual, pois, conforme Ada Grinover, "como a tutela processual adequada, em última análise, se perfaz por intermédio do procedimento adequado, nesses trabalhos o procedimento assume nova dimensão, sendo, ao lado do processo, instrumento para o atingimento da pacificação". ${ }^{5}$

Considerando que o processo é instrumento de concretização do direito material, afirma-se que se deve "partir da crise do direito material - ou seja, do conflito específico - para analisar (ou construir) a solução processual adequada". ${ }^{6}$ Assim, o processo deve se guiar por um procedimento adequado para a resolução do conflito. Então, partindo-se da constatação de que é impossível ao legislador prever todas as hipóteses de conflitos imagináveis e os procedimentos adequados para sua pacificação,7 a solução "consiste na possibilidade de flexibilização ou adaptação do procedimento, para que este se possa efetivamente levar à solução aderente à especial natureza do conflito". 8

\footnotetext{
4 GAJARDONI, Fernando F. Flexibilização procedimental: novo enfoque para o estudo do procedimento em matéria processual. Tese (Doutorado em Direito) - Universidade de São Paulo, São Paulo, 2007. p. 160.

GRINOVER, Ada P. Ensaio sobre a processualidade. Fundamentos para uma nova teoria geral do processo. Brasília: Gazeta, 2016. p. 3. GRINOVER, Ada P. Ensaio sobre a processualidade. Fundamentos para uma nova teoria geral do processo. p. 14.

"(...) apesar de o legislador ter considerado a diversidade das demandas ao tentar agrupá-las, a partir de critérios legalmente estabelecidos, vinculando-as a ritos processuais (ou procedimento) específicos, a sua atuação mostra-se insuficiente para abarcar a complexidade inerente às relações sociais, o que, em termos práticos, pode levar a um processamento ineficaz do feito." (ONO, Taynara T. A flexibilização do procedimento e sua abordagem na tramitação do novo Código de Processo Civil. Revista Eletrônica de Direito Processual, Rio de Janeiro, v. 16, n. 16, p. 664-683, jul./dez. 2015. p. 666). 
Sustenta-se que a flexibilização deve ser medida excepcional e submetida a requisitos relevantes. Primeiramente, impõe-se a atenção à sua finalidade, buscando-se aprimorar o procedimento para resolução mais célere e efetiva do conflito. Além disso, é essencial o respeito ao contraditório, ou seja, as partes devem ser cientificadas com antecedência sobre o novo rito procedimental adotado. Por fim, a decisão judicial que determina a flexibilização deve ser adequadamente motivada. ${ }^{9}$

Em regra, são elencadas três espécies de flexibilização procedimental: legislativa, judicial e consensual. A primeira seria estabelecida pelo próprio legislador, ou seja, a lei definiria opções procedimentais, conforme o caso concreto, de modo genérico ou alternativo. Depois, a flexibilização judicial ocorreria por decisão do juiz, de modo discricionário, ainda que fora das hipóteses legais. Por fim, consensual seria a adaptação procedimental determinada por acordo entre as partes envolvidas no processo. ${ }^{10}$

Entre as espécies de flexibilização, certamente a que tem sido explorada pela doutrina processual civil é a judicial, a qual "está intrinsecamente relacionada à possibilidade de adequação dos atos processuais às realidades do caso concreto, ainda que em desacordo com as normas formais positivadas". ${ }^{11}$ Resta claro que o ponto central, a inovação em destaque, é a permissão de desatenção ao rito ou à forma de atos previstos na legislação pátria, a partir de permissivos legais genéricos ou sem qualquer autorização normativa.

Após profundas discussões e impasses no trâmite do processo legislativo que originou o CPC de 2015, ${ }^{12}$ três dispositivos da nova legislação podem ser destacados em termos de flexibilização procedimental:

Art. 139. O juiz dirigirá o processo conforme as disposições deste Código, incumbindo-lhe: (...) VI - dilatar os prazos processuais e alterar a ordem de produção dos meios de prova, adequando-os às necessidades do conflito de modo a conferir maior efetividade à tutela do direito; (...)

Art. 190. Versando o processo sobre direitos que admitam autocomposição, é lícito às partes plenamente capazes estipular mudanças no procedimento para ajustá-lo às especificidades da causa e convencionar sobre os seus ônus, poderes, faculdades e deveres processuais, antes ou durante o processo.

Parágrafo único. De ofício ou a requerimento, o juiz controlará a validade das convenções previstas neste artigo, recusando-lhes aplicação somente nos casos de nulidade ou de inserção abusiva em contrato de adesão ou em que alguma parte se encontre em manifesta situação de vulnerabilidade.

9 GAJARDONI, Fernando F. Flexibilização procedimental: novo enfoque para o estudo do procedimento em matéria processual. Tese (Doutorado em Direito) - Universidade de São Paulo, São Paulo, 2007. p. 103-112.

10 GAJARDONI, Fernando F. Flexibilização procedimental: novo enfoque para o estudo do procedimento em matéria processual. p. 157-158.

11 ONO, Taynara T. A flexibilização do procedimento e sua abordagem na tramitação do novo Código de Processo Civil. Revista Eletrônica de Direito Processual. p. 669.

12 Sobre o processo legislativo em relação ao tema da flexibilização procedimental, ver: ONO, Taynara T. A flexibilização do procedimento e sua abordagem na tramitação do novo Código de Processo Civil. Revista Eletrônica de Direito Processual. p. 664-683. 
Art. 191. De comum acordo, o juiz e as partes podem fixar calendário para a prática dos atos processuais, quando for o caso.

$\S 1^{\circ} \mathrm{O}$ calendário vincula as partes e o juiz, e os prazos nele previstos somente serão modificados em casos excepcionais, devidamente justificados.

$\S 2^{\circ}$ Dispensa-se a intimação das partes para a prática de ato processual ou a realização de audiência cujas datas tiverem sido designadas no calendário.

Foram previstas, portanto, opções de flexibilização procedimental diretamente pelo julgador, para dilatar prazos ou alterar a ordem de produção de provas, ou por acordo entre as partes, possibilitando ampla margem de modificações procedimentais. Com relação aos poderes do julgador, importante ressaltar que o legislador optou por posição mais restritiva, tendo em vista que a redação original do projeto aprovado na Câmara dos Deputados previa que o juiz poderia "adequar as fases e os atos processuais às especificações do conflito, de modo a conferir maior efetividade à tutela do bem jurídico". ${ }^{13}$

Por outro lado, a flexibilização procedimental por acordo entre as partes permite maior amplitude. ${ }^{14}$ Afirma-se que "negociação acerca do procedimento possui fundamento no princípio da cooperação processual, que impõe a colaboração dos sujeitos processuais entre si, conjugando seus interesses em busca da solução da controvérsia". ${ }^{15}$

Além disso, como uma cláusula geral, aponta-se que, com base no art. $8^{\circ}$ do CPC, ${ }^{16}$ "o juiz tem o dever de amoldar o procedimento às circunstâncias do caso concreto, quando se fizer necessário e sempre com a devida ponderação". ${ }^{17}$ Assim, embora existam críticas, ${ }^{18}$ sustenta-se majoritariamente que a "flexibilização possui perfeita compatibilização com a função legitimante do procedimento e com o devido processo constitucional - material e formal". ${ }^{19}$

13 ONO, Taynara T. A flexibilização do procedimento e sua abordagem na tramitação do novo Código de Processo Civil. Revista Eletrônica de Direito Processual. p. 675

14 Sobre os negócios jurídicos processuais, ver: DIDIER JR., Fredie. Ensaios sobre os negócios jurídicos processuais. Salvador: Juspodivm 2018; CABRAL, Antonio do P. Convenções processuais. 2. ed. Salvador: Juspodivm, 2018. Em relação à aplicabilidade no processo penal: CABRAL, Antonio P. Acordos processuais no processo penal. In: CABRAL, Antonio P.; PACELLI, Eugênio; CRUZ, Rogério S. (Coords.) Coleção Repercussões do Novo CPC. Vol. 13, Processo Penal. Salvador: JusPodivm, 2016. p. 149-172.

15 PONTE, Marcelo D.; ROMÃO, Pablo F. Negócio jurídico processual e flexibilização do procedimento: as influências da autonomia privada no paradigma publicista do direito processual civil. Revista Eletrônica de Direito Processual, Rio de Janeiro, v. 16, n. 16, p. 305-334, jul./dez. 2015. p. 309. Assim também: WAMBIER, Luiz R. O modelo processual cooperativo e a flexibilização procedimental. Revista Eletrônica de Direito Processual, Rio de Janeiro, v. 18, n. 3, p. 238-255, jul./dez. 2017. p. 251.

16 Art. 8. $\stackrel{\mathrm{CPC} .}{\mathrm{A}}$ Ao aplicar o ordenamento jurídico, o juiz atenderá aos fins sociais e às exigências do bem comum, resguardando e promovendo a dignidade da pessoa humana e observando a proporcionalidade, a razoabilidade, a legalidade, a publicidade e a eficiência.

17 WAMBIER, Luiz R. O modelo processual cooperativo e a flexibilização procedimental. Revista Eletrônica de Direito Processual. p. 248.

18 "(...) os atos processuais que compõem o rito processual, de acordo com a maior parte da doutrina, devem estar previstos expressamente e em lei, pois a previsibilidade e a anterioridade do procedimento é que conferem à decisão judicial os penhores da legalidade e legitimidade, sendo dele requisitos inafastáveis." (GAJARDONI, Fernando F. Flexibilização procedimental: novo enfoque para o estudo do procedimento em matéria processual. p. 99).

19 CABRAL, Trícia N. X. Flexibilização procedimental. Revista Eletrônica de Direito Processual, Rio de Janeiro, v. 6, n. 6, p. 135-164, jul./dez. 2010. p. 140 


\section{TENSÕES E LIMITAÇÕES EM ÂMBITO PROCESSUAL PENAL: SOBRE AS DISTINÇÕES ESSENCIAIS DA DOGMÁTICA PROCESSUAL PENAL NA TEORIA GERAL DO PROCESSO}

Tradicionalmente, a doutrina afirma que o processo penal tutela direitos e valores indisponíveis e não passíveis de negociações. ${ }^{20}$ Contudo, o cenário brasileiro e internacional de expansão dos espaços de consenso, com mecanismos negociais como barganha e colaboração premiada, tem alterado tal perspectiva de um modo profundo. ${ }^{21}$ Cada vez mais ordenamentos jurídicos têm recorrido a acordos entre acusação e defesa, em que o imputado colabora com a persecução penal, conformando-se com a imputação, em troca de benefícios, como a redução da sanção punitiva. Percentuais cada vez mais representativos de casos são resolvidos por barganha e obtenção da confissão do acusado, representando até 90 por cento das condenações nos Estados Unidos 22 e 30 a 50 por cento em processos de crimes econômicos na Alemanha. ${ }^{23}$

Em termos de flexibilização procedimental penal, Scarance Fernandes sustenta que "o direito a um sistema de regras e princípios que conjuguem eficiência e garantia não representa direito a um procedimento certo, determinado e delineado, com todos os seus atos e fases, em sequência predeterminada, mas o direito a um procedimento assentado em alguns paradigmas extraídos de normas constitucionais do devido processo legal". ${ }^{24}$

Portanto, as ideias relacionadas à flexibilização procedimental permeiam o debate doutrinário no processo penal há certo tempo. Contudo, partindo da exposição apresentada no tópico anterior sobre as premissas teóricas de tal posicionamento, deve-se questionar a sua compatibilidade com a esfera criminal.

O processo penal apresenta diferenças consideráveis em relação ao processo civil. Focandose em um dos elementos centrais, a justiça criminal tutela os aspectos mais relevantes da vida em sociedade e, a partir da ideia de subsidiariedade, atua somente em interesses que não podem ser adequadamente resguardados pelos outros ramos do Direito. Junto a isso, o direito penal tem conexão estreita com as relações de poder e de desigualdades presentes na sociedade. Como apontado por Eugenio Zaffaroni, "a seletividade, a reprodução da violência, a criação de condições para maiores condutas lesivas, a corrupção institucionalizada, a concentração de poder, a verticalização social

20 GRINOVER, Ada P. Ensaio sobre a processualidade. Fundamentos para uma nova teoria geral do processo. p. 35.

21 Sobre isso, ver: VASCONCELLOS, Vinicius G. Barganha e Justiça Criminal Negocial. São Paulo: IBCCRIM, 2015; VASCONCELLOS, Vinicius G. Colaboração premiada no processo penal. 2. ed. São Paulo: RT, 2018.

22 ALSCHULER, Albert W. The prosecutor's role in plea bargaining. University of Chicago Law Review, v. 36, p. 50-112, 1968, p. 50. Há quem aponte que tal estatística chega a 95\% (LIPPKE, Richard L. The ethics of plea bargaining. Oxford: Oxford University Press, 2011. p. 1).

23 VASCONCELLOS, Vinicius G.; MOELLER, Uriel. Acordos no processo penal alemão: descrição do avanço da barganha da informalidade à regulamentação normativa. Boletín Mexicano de Derecho Comparado, v. 49, n. 147, p. 13-33, set./dez. 2016. p. 22.

24 FERNANDES, Antonio Scarance. Teoria geral do procedimento e o procedimento no processo penal. São Paulo: RT, 2005. p. 43. 
e a destruição das relações horizontais ou comunitárias não são características conjunturais, mas estruturais do exercício de poder de todos os sistemas penais". 25

Desse modo, a ideia de instrumentalidade do processo assume características específicas em tal panorama. Classicamente, tal construção, além de ressaltar a conexão entre direito material e processual, ${ }^{26}$ rompe as barreiras teóricas sobre os escopos jurídicos do processo e ressalta sua vertente social e política, segundo estabelecido por Cândido Dinamarco. ${ }^{27}$ Afirma-se que "a pacificação é o escopo magno da jurisdição e, por consequência, de todo o sistema processual (uma vez que todo ele pode ser definido como a disciplina jurídica da jurisdição e seu exercício)". ${ }^{28}$

Sem dúvidas, a teoria instrumentalista apresenta importantes contribuições à dogmática processual. Contudo, a supervalorização dos escopos sociais, como a resolução de conflitos e a pacificação da sociedade, com a redução da importância das categorias próprias do processo, finda por acarretar invariáveis prejuízos à construção de uma dogmática processual penal constitucional e convencionalmente orientada. A crença na capacidade de o processo penal ser um meio de resolução de conflitos de tamanha complexidade ou de pacificação social por certo consolida um mito, ${ }^{29}$ que perfaz uma "ferida narcísica" ${ }^{30}$ das ciências criminais. Com relação à esfera material, resta claro que o desvelamento das cifras ocultas de criminalidade findou por relevar que "não há mínima correspondência, no plano da eficácia, entre o processo de criminalização primária e o de criminalização secundária", ou seja, a pretensão de tratamento igualitária do direito penal como resposta ao cometimento de um delito se mostra ilusória na atuação prática do sistema criminal. ${ }^{31}$ Ademais, embora se possa afirmar que exista um conflito de interesses entre as partes processuais na justiça criminal, a sua solução não é a função essencial do processo penal, tanto que ela é irrelevante para a necessidade do processo à imposição de uma sanção punitiva pelo Estado. ${ }^{32}$

Assim, não se pode aceitar uma hipertrofia da ideia de "instrumentalidade das formas", em que se esvaziam nulidades ocasionadas por defeitos em atos, sob o argumento de que a proteção das formas não pode superar os escopos finais do processo, como a aplicação do direito material ou a resolução do conflito. Por exemplo, tais leituras exageradas findam por supervalorizar a regra da necessidade de prejuízo para reconhecimento de nulidades processuais, o que, em interpretação corriqueira dos tribunais brasileiros, inviabiliza quase integralmente a proteção das formas procedimentais em seu

25 ZAFFARONI, Eugenio Raúl. Em busca das penas perdidas. A perda de legitimidade do sistema penal. Rio de Janeiro: Revan, 2014. p. 15.

26 "Falar em instrumentalidade do processo, pois, não é falar somente nas suas ligações com a lei material. O Estado é responsável pelo bemestar da sociedade e dos indivíduos que a compõem: e, estando o bem-estar social turbado pela existência de conflitos entre as pessoas, ele se vale do sistema processual para, eliminando os conflitos, devolver à sociedade a paz desejada." (CINTRA, Antonio C. A.; GRINOVER, Ada P.; DINAMARCO, Cândido R. Teoria Geral do Processo. 24a ed. São Paulo: Malheiros, 2008. p. 47).

DINAMARCO, Cândido Rangel. A instrumentalidade do processo. 15. ed. São Paulo: Malheiros, 2013. p. 182.

CINTRA, Antonio C. A.; GRINOVER, Ada P.; DINAMARCO, Cândido R. Teoria Geral do Processo. p. 30.

CASARA, Rubens R. R. Mitologia Processual Penal. São Paulo: Saraiva, 2015. p. 202.

CARVALHO, Salo. Antimanual de criminologia. 3. ed. Rio de Janeiro: Lumen Juris, 2010. p. 91-110.

CARVALHO, Salo. Antimanual de criminologia. p. 93.

VASCONCELLOS, Vinicius G. Lide na justiça criminal? Sobre a importância do conflito de interesses entre as partes processuais e sua irrelevância para a necessidade do Processo Penal. Revista Brasileira de Ciências Criminais, São Paulo, v. 119, p. $165-199$, abr./jun. 2016. p. $192-194$. 
aspecto de garantia de direitos fundamentais. ${ }^{33}$ Diante da realidade contraproducente e seletiva do Direito Penal, o processo não pode ter outra função senão limitar o poder punitivo estatal para contenção de danos. ${ }^{34}$ Sustenta-se que o fundamento do processo penal, sua razão de existir, é o reconhecimento de que, em um Estado democrático de direito, uma sanção penal (especialmente, prisão) somente pode ser imposta após a obtenção de uma condenação definitiva com total respeito às regras do devido processo penal. ${ }^{35} \mathrm{E}$, assim, ele adquire o sentido de ser um instrumento de limitação do poder punitivo ao condicionar a aplicação de uma sanção penal ao seu transcorrer e encerramento, em respeito às regras do devido processo. ${ }^{36} \mathrm{Ou}$ seja, o processo penal se fundamenta no princípio da necessidade (nulla poena sine iudicio), ${ }^{37}$ como caminho necessário para a concretização de uma sanção criminal, efetivando-se como limitação do poder punitivo estatal. ${ }^{38}$ Trata-se de sentido compartilhado com os diplomas internacionais de proteção de direitos humanos, ${ }^{39}$ que consolida uma perene tensão entre legitimação e contenção do sistema punitivo. ${ }^{40}$

No processo penal, a expansão dos poderes do julgador para guiar o processo e a formação da prova é problematizada por grande parte da doutrina, ao passo que amplia os espaços para arbitrariedades. ${ }^{41}$ Sustentar-se que a função do processo penal é resolver o conflito e pacificar a sociedade a partir da busca pela verdade acarreta riscos à imparcialidade do julgador e à efetividade do contraditório na justiça criminal. ${ }^{42}$

33 GLOECKNER, Ricardo Jacobsen. Nulidades no Processo Penal. Introdução principiológica à teoria do ato processual irregular. Salvador: JusPodivm, 2013. p. 247-261 e 475-484; PAULA, Leonardo Costa de. As Nulidades no Processo Penal. Sua compreensão por meio da afirmação do direito como controle ao poder de punir. Curitiba: Juruá, 2013. p. 83-121. Ver também: BINDER, Alberto M. El incumplimiento de las formas procesales: elementos para uma crítica a la teoria unitaria de las nulidades em el proceso penal. Buenos Aires: Ad-Hoc S.R.L. 2000; BIZZOTTO, Alexandre. Lições de Direito Processual Penal. Curitiba: Observatório da Mentalidade Inquisitória, 2019.

34 "(...) o direito penal e processual penal resultam ainda necessários como alternativas à política, apresentando-se como tecnologia de minimização da violência e do arbítrio punitivo" (CARVALHO, Salo. Antimanual de criminologia. p. 152). Conforme Ricardo Gloeckner, "se o poder é tendente à expansão, cabe ao processo limitar tal poder punitivo, de molde a minimizar ao máximo os riscos de lesão aos direitos primordiais do acusado" (GLOECKNER, Ricardo Jacobsen. Nulidades no Processo Penal. Introdução principiológica à teoria do ato processual irregular. p. 30).

35 “(...) para que se possa impor uma pena não é suficiente que haja uma infração (delito ou falta), mas também é necessário que haja processo. A pena não é somente um efeito (jurídico) do delito, mas, por outro lado, é um efeito do processo" (GÓMEZ ORGANEJA, Emilio. Comentarios a la Ley de Enjuiciamiento Criminal. Tomo I. Barcelona: Bosch, 1951. p. 27) (tradução livre). Sobre isso: MONTERO AROCA, Juan. Proceso penal y libertad. Ensayo polémico sobre el nuevo proceso penal. Madrid: Thomson Civitas, 2008. p. 25-36 e 61-64.

36 BINDER, Alberto M. La implementación de la nueva justicia penal adversarial. Buenos Aires: Ad-Hoc, 2012. p. 74; CASARA, Rubens R. R.; MELCHIOR, Antonio Pedro. Teoria do Processo Penal brasileiro. Dogmática e crítica: conceitos fundamentais. Vol. 1. Rio de Janeiro: Lumen Juris, 2013. p. 258.

37 GIACOMOLLI, Nereu José. O Devido Processo Penal. Abordagem conforme a Constituição Federal e o Pacto de São José da Costa Rica. São Paulo: Atlas, 2014. p. 401-406; LOPES JR., Aury. Direito Processual Penal. 9. ed. São Paulo: Saraiva, 2012. p. 85-88; CASARA, Rubens R. R.; MELCHIOR, Antonio Pedro. Teoria do Processo Penal brasileiro. Dogmática e crítica: conceitos fundamentais. p. 134-136.

38 "Tudo isso significa que (no plano do processo de tipo condenatório, pelo menos) a jurisdição deveria ser apresentada não exatamente como poder, mas como autêntico contra-poder, que tensiona com o poder punitivo, para limitá-lo, e essa é a única maneira possível de assegurar a efetividade do direito de defesa, conferindo-lhe a musculatura necessária para confrontar-se com a força do Estado-acusador" (DUCLERC, Elmir. Por uma teoria do processo penal. Florianópolis: Empório do Direito, 2015. p. 76).

39 PASTOR, Daniel R. El llamado "impacto" de los tratados de derechos humanos en el derecho interno con especial referencia al derecho procesal penal. Cuadernos de Doctrina y Jurisprudencia Penal, Buenos Aires, ano 05, n. 09, p. 41-57, 1999. p. 44.

40 "O problema é idêntico em matéria penal: as garantias referidas ao poder penal do Estado, embora pretendam colocar limites precisos a esse poder, também Ihe legitimam, pois reconhecem ele como seu pressuposto, como substrato ao qual essas garantias se referem. O problema é, em uma determinada época ou para um Estado concreto, qual das duas visões alcança maior sustentação e aplicação prática: a que legitima o poder estatal ou aquela que o limita." (MAIER, Julio B. J. Derecho Procesal Penal. Tomo I. 2. ed. Buenos Aires: Del Puerto, 2004. p. 475) (tradução livre).

41 Sobre isso: LOPES JR., Aury. Direito Processual Penal. p. 136.

42 KHALED JR., Salah H. A busca da verdade no processo penal. Para além da ambição inquisitorial. São Paulo: Atlas, 2013. p. 362. 
Diante do exposto, resta claro que no processo penal a forma é garantia, ${ }^{43}$ de modo que o desrespeito a uma formalidade prevista na Lei deve acarretar uma presunção de violação de direito fundamental. E, nesse sentido, a legalidade assume posição de indispensabilidade e primazia na dogmática processual penal. Considerando-se que o poder tende ao abuso, a sua divisão, com controle e limitações recíprocas, é medida que se impõe. Isso ocorre com a estruturação do processo em um sistema acusatório (com a divisão dos poderes entre julgador, acusação e defesa) e com a submissão do exercício do poder punitivo (Estado-juiz) aos limites impostos pela Lei (poder legislativo como representante do povo).

Assim, em muitos casos, alterações na sequência procedimental, por mais que para alguns possam parecer meras formalidades, acarretam violações a direitos fundamentais. Por exemplo, no processo penal o interrogatório do réu deve ser o último ato da fase de produção de provas, pois isso é pressuposto para o exercício efetivo da ampla defesa e do contraditório. Por outro lado, a sistemática de exame cruzado das testemunhas, em que as partes dirigem os questionamentos e o julgador atua somente de modo subsidiário, é expressão de proteção do contraditório e da imparcialidade. ${ }^{44}$

No processo penal, o respeito à legalidade, ou seja, a submissão do exercício do poder punitivo aos limites previstos em lei, é premissa essencial em um Estado democrático de Direito. Portanto, retomando-se as classificações das espécies de flexibilização procedimental apontadas no item anterior, a possibilidade de flexibilizações judiciais, sem qualquer autorização normativa, mostra-se problemática ao ignorar por completo a necessidade de respeito à legalidade.

Entretanto, há quem sustente o cabimento de flexibilizações judiciais, ainda que ausente autorização legal. Para tanto, afirma-se que os seguintes parâmetros devem ser considerados: legalidade, proporcionalidade e razoabilidade. ${ }^{45}$ Primeiramente, mostra-se contraditório afirmar que a legalidade deve ser observada exatamente quando inexiste previsão legal para a alternativa decidida pelo julgador. Por outro lado, os critérios da proporcionalidade e da razoabilidade são relevantes à análise pretendida, mas, em regra, demasiadamente abertos em sua definição conceitual, o que finda por autorizar espaços abusivos de discricionariedade.

Com relação às hipóteses de flexibilização consensual, em que as partes negociam por meio de convenções processuais, deve-se adotar postura cautelosa, buscando a sua limitação. Como visto no tópico anterior, tais institutos fundamentam-se em uma concepção de dever de cooperação das

\footnotetext{
43 LOPES JR, Aury. Direito Processual Penal. p. 1134-1138.

44 Sobre o modelo de produção de prova oral em exame cruzado, ver: ARANTES FILHO, Marcio G. B. O cross-examination como procedimento probatório para produção de prova testemunhal no direito processual penal brasileiro. 2016. Tese (doutorado em direito) - Faculdade de Direito, Universidade de São Paulo, São Paulo. p. 58-118.

45 DEZEM, Guilherme M. A flexibilização no processo penal. Tese (Doutorado em Direito) - Universidade de São Paulo, São Paulo, 2013. p. 47.
} 
partes ao processo. Todavia, em âmbito penal, consolida-se com extrema importância o direito à não autoincriminação, de modo que à defesa não podem ser impostos deveres de colaboração à persecução penal. ${ }^{46}$

Como já exposto, a justiça criminal negocial é permeada por aporias que ocasionam indevidas coerções, potencializando o poder coercitivo do processo penal e a possibilidade de prejuízos a acusados inocentes. ${ }^{47}$ Assim, acordos para modificações procedimentais, ainda que pretensamente voluntários, devem ser analisados com cautela e submetidos a limitações previstas em lei.

\section{CONSIDERAÇÕES FINAIS}

Diante do exposto neste trabalho, retomam-se os problemas que guiaram a pesquisa: 1) as premissas teóricas da flexibilização procedimental do processo civil podem ser transplantadas ao processo penal?; 2) considerando eventuais distinções entre tais instrumentos e suas funções, a relativização da necessidade de respeito à legalidade pode ser aceita no processo penal?

1. As funções do processo civil são distintas em relação ao processo penal, de modo que este se caracteriza em essência como um instrumento de limitação do poder punitivo, ao passo que as demais funções de reconstrução dos fatos passados e aplicação do direito material mostram-se colaterais, embora também relevantes.

2. As premissas de aplicação da flexibilização procedimental não podem ser transplantadas da esfera civil à penal sem revisão crítica. Como instrumento de limitação do poder punitivo, o processo penal deve ser estruturado a partir do respeito à legalidade, acarretando a necessidade de previsão em lei das eventuais opções procedimentais e de flexibilização das formas processuais, com critérios objetivos para sua aplicação e mecanismos de controle adequados.

3. Assim, possibilidades de flexibilizações procedimentais legais alternativas e consensuais devem ser analisadas com cautela e limitadas, ao passo que acarretam riscos às premissas do processo penal constitucional e convencionalmente orientado.

\section{REFERÊNCIAS DAS FONTES CITADAS}

ALSCHULER, Albert W. The prosecutor's role in plea bargaining. University of Chicago Law Review, v. 36, p. 50-112, 1968.

ARANTES FILHO, Marcio G. B. O cross-examination como procedimento probatório para produção de prova testemunhal no direito processual penal brasileiro. 2016. Tese (doutorado em direito) - Faculdade de Direito, Universidade de São Paulo, São Paulo.

46 Sobre isso, ver: QUEIJO, Maria Elizabeth. O direito de não produzir prova contra si mesmo. 2. ed. São Paulo: Saraiva, 2012.

47 VASCONCELLOS, Vinicius G. Barganha e Justiça Criminal Negocial. p. 143-209. 
BINDER, Alberto M. El incumplimiento de las formas procesales: elementos para uma crítica a la teoria unitaria de las nulidades em el proceso penal. Buenos Aires: Ad-Hoc S.R.L., 2000.

BINDER, Alberto M. La implementación de la nueva justicia penal adversarial. Buenos Aires: Ad-Hoc, 2012.

BIZZOTTO, Alexandre. Lições de Direito Processual Penal. Curitiba: Observatório da Mentalidade Inquisitória, 2019.

CABRAL, Antonio P. Acordos processuais no processo penal. In: CABRAL, Antonio P.; PACELLI, Eugênio; CRUZ, Rogério S. (Coords.). Coleção Repercussões do Novo CPC. Vol. 13, Processo Penal. Salvador: JusPodivm, 2016.

CABRAL, Antonio do P. Convenções processuais. 2. ed. Salvador: Juspodivm, 2018.

CABRAL, Trícia N. X. Flexibilização procedimental. Revista Eletrônica de Direito Processual, Rio de Janeiro, v. 6, n. 6, p. 135-164, jul./dez. 2010.

CARVALHO, Salo. Antimanual de criminologia. 3. ed. Rio de Janeiro: Lumen Juris, 2010.

CASARA, Rubens R. R. Mitologia Processual Penal. São Paulo: Saraiva, 2015.

CASARA, Rubens R. R.; MELCHIOR, Antonio Pedro. Teoria do Processo Penal brasileiro. Dogmática e crítica: conceitos fundamentais. Vol. 1. Rio de Janeiro: Lumen Juris, 2013.

CINTRA, Antonio C. A.; GRINOVER, Ada P.; DINAMARCO, Cândido R. Teoria Geral do Processo. 24. ed. São Paulo: Malheiros, 2008.

DEZEM, Guilherme M. A flexibilização no processo penal. Tese (Doutorado em Direito) - Universidade de São Paulo, São Paulo, 2013.

DIDIER JR., Fredie. Ensaios sobre os negócios jurídicos processuais. Salvador: Juspodivm, 2018.

DINAMARCO, Cândido Rangel. A instrumentalidade do processo. 15. ed. São Paulo: Malheiros, 2013.

DUCLERC, Elmir. Por uma teoria do processo penal. Florianópolis: Empório do Direito, 2015.

FERNANDES, Antonio Scarance. Teoria geral do procedimento e o procedimento no processo penal. São Paulo: RT, 2005.

GAJARDONI, Fernando F. Flexibilização procedimental: novo enfoque para o estudo do procedimento em matéria processual. Tese (Doutorado em Direito) - Universidade de São Paulo, São Paulo, 2007.

GIACOMOLLI, Nereu José. O Devido Processo Penal. Abordagem conforme a Constituição Federal e o Pacto de São José da Costa Rica. São Paulo: Atlas, 2014.

GLOECKNER, Ricardo Jacobsen. Nulidades no Processo Penal. Introdução principiológica à teoria do ato processual irregular. Salvador: JusPodivm, 2013.

GÓMEZ ORGANEJA, Emilio. Comentarios a la Ley de Enjuiciamiento Criminal. Tomo I. Barcelona: Bosch, 1951.

GRINOVER, Ada P. Ensaio sobre a processualidade. Fundamentos para uma nova teoria geral do processo. Brasília: Gazeta, 2016.

KHALED JR., Salah H. A busca da verdade no processo penal. Para além da ambição inquisitorial. São Paulo: Atlas, 2013. LIPPKE, Richard L. The ethics of plea bargaining. Oxford: Oxford University Press, 2011.

MAIER, Julio B. J. Derecho Procesal Penal. Tomo I. 2. ed. Buenos Aires: Del Puerto, 2004.

MONTERO AROCA, Juan. Proceso penal y libertad. Ensayo polémico sobre el nuevo proceso penal. Madrid: Thomson Civitas, 2008. 
LOPES JR., Aury. Direito Processual Penal. 9. ed. São Paulo: Saraiva, 2012.

ONO, Taynara T. A flexibilização do procedimento e sua abordagem na tramitação do novo Código de Processo Civil. Revista Eletrônica de Direito Processual, Rio de Janeiro, v. 16, n. 16, p. 664-683, jul./dez. 2015. https://doi.org/10.12957/ redp.2015.18733

PASTOR, Daniel R. El llamado "impacto" de los tratados de derechos humanos en el derecho interno con especial referencia al derecho procesal penal. Cuadernos de Doctrina y Jurisprudencia Penal, Buenos Aires, ano 05, n. 09, p. 41-57, 1999.

PAULA, Leonardo Costa de. As Nulidades no Processo Penal. Sua compreensão por meio da afirmação do direito como controle ao poder de punir. Curitiba: Juruá, 2013.

PONTE, Marcelo D.; ROMÃO, Pablo F. Negócio jurídico processual e flexibilização do procedimento: as influências da autonomia privada no paradigma publicista do direito processual civil. Revista Eletrônica de Direito Processual, Rio de Janeiro, v. 16, n. 16, p. 305-334, jul./dez. 2015. https://doi.org/10.12957/redp.2015.19968

QUEIJO, Maria Elizabeth. 0 direito de não produzir prova contra si mesmo. 2. ed. São Paulo: Saraiva, 2012.

VASCONCELLOS, Vinicius G. Barganha e Justiça Criminal Negocial. São Paulo: IBCCRIM, 2015.

VASCONCELLOS, Vinicius G. Lide na justiça criminal? Sobre a importância do conflito de interesses entre as partes processuais e sua irrelevância para a necessidade do Processo Penal. Revista Brasileira de Ciências Criminais, São Paulo, v. 119, p. 165-199, abr./jun. 2016.

VASCONCELLOS, Vinicius G. Colaboração premiada no processo penal. 2. ed. São Paulo: RT, 2018.

VASCONCELLOS, Vinicius G.; MOELLER, Uriel. Acordos no processo penal alemão: descrição do avanço da barganha da informalidade à regulamentação normativa. Boletín Mexicano de Derecho Comparado, v. 49, n. 147, p. 13-33, set./dez. 2016. https://doi.org/10.22201/iij.24484873e.2016.147.10638

WAMBIER, Luiz R. O modelo processual cooperativo e a flexibilização procedimental. Revista Eletrônica de Direito Processual, Rio de Janeiro, v. 18, n. 3, p. 238-255, jul./dez. 2017. https://doi.org/10.12957/redp.2017.31696

ZAFFARONI, Eugenio Raúl. Em busca das penas perdidas. A perda de legitimidade do sistema penal. Rio de Janeiro: Revan, 2014.

RECEBIDO EM: 24/12/2018

APROVADO EM: 07/03/2020 